\title{
Antiracism Glossary for Education and Life
}

Richa Pokhrel, Center for Student Learning, College of Charleston

Mursalata Muhammad, English Department, Grand Rapids Community College

Juan Jimenez, General Studies \& Services, Western Technical College

Cassandra Green, Office of Student Success, Delaware State University

Sarah Felber, Writing Department, University of Maryland Global Campus

Chardin Claybourne, Learning Lab and Tutoring Services, Henry Ford College

WyKeshia Atkins, Learning Assistance Programs, Southeast Missouri State University

David R. Arendale, Curriculum and Instruction Department, University of Minnesota-Twin Cities

https://doi.org/10.36896/4.1sc1

\section{ABSTRACT}

To create an antiracism glossary, a team of scholars from Colleagues of Color for Social Justice (CCSJ) identified and defined 48 terms relating to racism and antiracism based on careful review of existing race-related glossaries, scholarly articles, and widely-read books on the topic. This glossary of terms illustrates the daily and pervasive nature of racism that people of color experience and fills a demonstrable gap in resources of this type for college learning assistance centers and programs. The purpose is to recognize and explain terms related to attitudes, behaviors, and policies that impact people's lives, particularly within academia. The glossary lists the terms in alphabetical order with multiple definitions from various resources and easy to understand examples drawn from personal lives, communities, and professional experiences in educational settings.

Keywords: antiracism, antiracist, glossary, learning assistance, people of color, racism

T

his Antiracism Glossary for Education and Life was designed for a variety of readers. It may be useful for those working in the classroom, administrative roles, student service units, learning assistance, educational equity programs (such as academic bridge programs, GEAR UP, and TRIO), and other roles in education at the secondary and postsecondary level. For people of color (POC), the words, definitions, and examples may resonate with shared experience. For White people, the glossary serves to reveal the often day-today experience for POC and the challenge of living in America. This glossary, then, can serve not only as a resource for educators and practitioners, but also as a foundation on which future publications can expand.

An essential part of any glossary are the terms and examples being used. We believe the

\section{We expect those silences to be filled \\ by the lived experiences of other \\ marginalized POC in future editions of this glossary or others like it.}

contribution of this glossary is the extensive examples in personal and educational settings that illustrate the definitions. In the case of the antiracism glossary, the coauthors contributed many examples from personal experiences, providing readers with real-life representations of what these terms mean moving beyond neutral denotations. While some examples were obtained from other glossaries and publications, the majority of coauthors drew from their lived experiences as POC. The examples that accompany these glossary definitions are a sample of the types of occurrences many POC experience in their daily lives.

Readers and users of this antiracism glossary will (and should) notice a number of silences or absent voices in the examples that accompany the terms. We, the coauthors, recognize those silent spaces. We expect those silences to be filled by the lived experiences of other marginalized POC

\section{Corresponding Author}

Dr. David Arendale, Curriculum and Instruction University of Minnesota-Twin Cities

123 Christenson Court NE | Fridley, MN 55432

Email: Arendale@umn.edu 
in future editions of this glossary or others like it. Unlike historical U.S. publication practices which have frequently silenced POC, we acknowledge the silent spaces opened by the examples included in this glossary. We intentionally avoid the habit of appropriation by not attempting to fill those silent spaces with experiences from other peoples' lives. We know those silent spaces belong to others. We offer this edition as an invitation for other POC to fill those silences with their authentic, lived experiences. We understand this offer destines this edition of our glossary to continuous improvement and leaves our work open. While the concept of racism is universal, it can be expressed and experienced-for many reasons-in ways too varied and voluminous for a comprehensive listing in this glossary. Future CCSJ publications will explore their experiences in deeper detail.

Many coauthors of this glossary, in sharing their examples, remarked how revisiting these experiences served to trigger the dormant memories and unearth the trauma. Kendi (2019) calls the unending and repeated daily events of racism abuse. The daily onslaught of microaggressions and macroaggressions has a cumulative deleterious effect on the emotional and physical health of POC. This glossary is a resource, and users should be considerate in its application. It may be inadvisable for a White person to ask colleagues or friends who are people of color if these examples are true or if this has happened to them. These authentic examples may be triggers for their traumatic memories to resurface. Instead, watch a documentary on racism, study one or more of the widely recommended books (Diangelo, 2018; Kendi, 2019; Oluo, 2019; Perkins, 2018), and carefully listen to POC who initiates the conversation. It requires an investment of time and a sincere desire to engage actively in learning-and then to use the newly-acquired knowledge. Two recommended short readings include McCoy's (2020) "The Life of a Black Academic: Tired and Terrorized" and Robert's (2020) "White Academia: Do Better."

Keeping current with the rapid changes in the field of education is essential. The words we use to discuss the changes that are occurring and must occur can make a difference in the policy-making decision process and offer practical guidance to educators at all levels and in all job roles. This glossary is our response to the disenfranchisement of POC in education. We hope it can play a role in furthering the conversation and continuing the path to equity for all. We close with the final words shared by Kendi from How to Be an Antiracist (2019):

Racist power is not godly. Racist policies

are not indestructible. Racial inequities are not inevitable. Racist ideas are not natural to the human mind... But racism is one of the fastest spreading and most fatal cancers humanity has ever known... When we lose hope, we are guaranteed to lose. But if we ignore the odds and fight to create an antiracist world, then we give humanity a chance to one day survive, a chance to live in communion, a chance to be forever free. (p. 238)

\section{Antiracism Glossary for Education and Life}

Throughout the glossary, words which are capitalized indicate that they are defined elsewhere within the glossary document. People of Color is abbreviated as POC except in direct quotations throughout this document. The examples that accompany the glossary definitions are not an exhaustive list of lived experiences of African, Asian/Pacific Islanders, Hispanic, Indigenous, Latinx, and Multi-racial people.

acculturation (sometimes called additive acculturation or bicultural acculturation)

1. Definitions: (a) Immigrants to the United States are provided time for them to adjust to the new culture and the school system while maintaining connections to their heritage and country of origin or connections with the cultural communities of marginalized school children (Makarova \& Birman, 2016); and (b) maintaining bilingual and bicultural heritage for school children.

2. Examples: (a) Maintaining country of origin heritage through class discussions, reading assignments, and class projects; and (b) honoring the writing style familiar to the students rather than standard written English.

3. Compare with ASSIMILATION (adjective and noun).

\section{affirmative action}

1. Definitions: (a) "Set of procedures designed to eliminate unlawful DISCRIMINATION among applicants, remedy the results of such prior DISCRIMINATION, and prevent such DISCRIMINATION in the future. Applicants may be seeking admission to an educational program or looking for professional employment. In modern American jurisprudence, it typically imposes remedies against DISCRIMINATION on the basis of, at the very least, RACE, creed, color, and national origin. While the concept of AFFIRMATIVE ACTION has existed in America since the 19th century, it first appeared in its current form in President Kennedy's 
Executive Order 10925 issued in 1961. Employers who contract with the government or who otherwise receive federal funds are required to document their AFFIRMATIVE ACTION practices and metrics. It is also a remedy, under the Civil Rights Act of 1964, where a court finds that an employer has intentionally engaged in DISCRIMINATORY practices" (Legal Information Institute, n.d., para. 1-2); and (b) "remedy to address past practices of DISCRIMINATION. AFFIRMATIVE ACTION in the employment arena describes the efforts of an organization to recruit and advance qualified people of color, women, persons with disabilities, and covered veterans. Required of federal contractors and subcontractors, AFFIRMATIVE ACTION also is permissible voluntarily where it is based on documented underutilization of women and people of color. AFFIRMATIVE ACTION in education refers to admissions policies and practices that provide equal access to education for those groups that have been historically excluded or underrepresented" (Diversity Advisory Council, n.d., section A, para. 4).

2. Examples: (a) Hiring a larger percentage of students of color than is represented by the institution's employees for staff and student paraprofessional positions if the college has historically been found to engage in DISCRIMINATION in hiring practices; (b) admitting a higher percent of historically-underrepresented students due to past DISCRIMINATORY admissions policies; (c) requiring a college to create a diversity hiring committee due to being found guilty of historically DISCRIMINATORY hiring practices; and (d) AFFIRMATIVE ACTION becoming a quota system for hiring Blacks or POCs in education. I (a Black woman) was hired as an Academic Advisor in a predominately White institution learning center because, according to the administrator, "We need a Black woman." They had one position left and had already hired a Black male. To fulfill the quota or in the name of AFFIRMATIVE ACTION, they needed a Black woman to meet the quota. Please do not get me wrong; it was my start in higher education. I ignored the assertion because I was about to graduate with my master's degree and needed a job to stay in the area. However, what started as a corrective program against discriminatory hiring practices within the state system of higher education schools, actually became a systemic and oppressive racial quota system whereby if you are hired, it is because you are Black or a person of color. I experienced the same at two smaller and private predominantly White institutions, where, upon my hiring, I was told by the White hiring administrators that I would "diversify the campus." Unfortunately, that is all they expected from me. Any display of intelligence or abilities to perform the job was marginalized.

ally

1. Definitions: (a) "A person who supports a group other than their own" (Berkner Boyt, 2020, para. 10) identities, such as gender, RACE, religion, sex; and (b) a person who acknowledges disadvantages and oppression of other groups and takes action to stand with them and oppose the oppression (W.K. Kellogg Foundation, n.d.-a).

2. Examples: (a) Speaking up on behalf of POC during conversations when others make disparaging comments, MICROAGGRESSION behaviors, jokes, or stereotypical statements whether POC are present or not; (b) participating in meetings hosted by POC that raise awareness about issues of identity (racial, sexual, etc.); (c) displaying posters that advocate for social justice on the learning center walls; (d) displaying a welcome poster on the learning center wall with the word "welcome" in languages spoken by members of the student body; (e) asking questions of POC "like 'what do I need to know,' 'how can I help,' and 'what can we do together?'” (Ludema \& Johnson, 2020, Don't be paternalistic section); (f) taking time to read books and watch videos on racial topics (history, slavery, systemic racism, etc.) and avoid asking POC to explain complex racial issues to you; (g) marching in a Pride Parade to advocate for an "annual audit of pay equity" (Ludema \& Johnson, 2020, Do take ally-like actions section); (h) taking actions that create an environment so that POC "speak for themselves" (Ludema \& Johnson, 2020, Don't speak for others section); (i) responding when the leader of the campus LBGTQ affinity group contacts you to offer support to the goals of the affinity group for Black employees; (j) using authority as the Resident Hall Assistant to confront students on the dorm floor who are dressed up as border patrol and migrants at the border and stop the activity, and using this incident as opportunity to inform all residents that this activity is not appropriate or acceptable; 
and $(k)$ as a South Asian woman marching at various Black Lives Matter protests while holding up a sign saying "South Asians for Black Lives;" and (I) attending campus and social activities hosted by POC.

3. Compare with ANTIRACISM (verb), EQUALITY, EQUITY, and SOCIAL JUSTICE.

\section{antiracism}

1. Definition: "The work of actively opposing racism by advocating for changes in political, economic, and social life. Anti-racism tends to be an individualized approach, and set up in opposition to individual racist behaviors and impacts" (Race Forward, 2015, p. 25).

2. Example: Report any acts of DISCRIMINATION to the institution Dean of Students or Title IX Officer.

3. Compare with ALLY, ANTIRACIST (noun), ETHNIC ANTIRACISM, SPACE ANTIRACISM, and SOCIAL JUSTICE.

antiracist (adjective)

1. Definition: Having qualities or features that promote or express an ANTIRACIST IDEA.

2. Examples: (a) Ensuring that employment opportunities are advertised to all faculty, staff, and students who may be interested, and (b) using an ANTIRACIST reading practice that "helps the reader identify the habits of language being used and inquire into where those habits come from in the larger world" in order to "understand better the language habits we participate in, and whether and how those habits participate in RACISM and White language supremacy" (Inoue, 2020, p. 135).

3. Compare with ANTIRACIST (noun) and BEHAVIORAL ANTIRACIST.

\section{antiracist (noun)}

1. Definitions: (a) "Supports an ANTIRACIST policy through their action or expressing an ANTIRACIST IDEA" (Kendi, 2019, p. 11); (b) "expresses the idea that racial groups are equals and none needs developing, and is supporting policy that reduces racial inequity" (Kendi, 2019, p. 24); (c) "conscious decision to make frequent, consistent, equitable choices daily. These choices require ongoing self-awareness and self-reflection as we move through life. In the absence of making ANTIRACIST choices, we (un)consciously uphold aspects of White supremacy, White-dominant culture, and unequal institutions and society. Being RACIST or ANTIRACIST is not about who you are; it is about what you do" (National Museum of African American History and Culture, n.d., para. 8).
2. Examples: See examples from BEHAVIORAL ANTIRACIST and CULTURAL ANTIRACIST.

3. Compare with ANTIRACIST (adjective) and BEHAVIORAL ANTIRACIST.

\section{antiracist discrimination}

1. Definition: "The defining question is whether the DISCRIMINATION is creating EQUITY or inequity. If DISCRIMINATION is creating EQUITY, then it is ANTIRACIST. If DISCRIMINATION is creating inequity, then it is RACIST. Someone reproducing inequity through permanently assisting an overrepresented RACIAL group into wealth and power is entirely different than someone challenging that inequity by temporarily assisting an underrepresented RACIAL group into relative wealth and power until EQUITY is reached. The only remedy to RACIST DISCRIMINATION is ANTIRACIST DISCRIMINATION" (Kendi, 2019, p. 19).

2. Examples: (a) Establishing minimum requirements for a part-time or full-time position, use minimum criteria for selecting the initial candidate pool for hiring tutors, study group leaders, mentors, and professional staff (i.e., screening candidates into the interview pool and not screening candidates out); (b) not excluding job candidates due to a lack of some qualifications if those could be addressed through professional development; and (c) ensuring that the teaching staff, professional staff, and the student paraprofessionals (tutors, study group leaders, coaches, etc.) display demographic diversity that equals or exceeds the diversity of the general student body.

3. Compare with AFFIRMATIVE ACTION, ANTIRACISM, DISCRIMINATION, EQUALITY, and EQUITY.

\section{assimilationist (noun)}

1. Definition: "One who is expressing the RACIST IDEA that a racial group is culturally or behaviorally inferior and is supporting cultural or behavioral enrichment programs to develop that racial group" (Kendi, 2019, p. 24).

2. Examples: (a) A White person who feels guilt from growing up in a PRIVILEGED background decides to become involved in an EQUITY program to help students who the person believes are suffering from educational deficits and are academically inferior because of their ethnicity; (b) Indigenous children are forced to attend boarding schools under the Civilization Fund Act of 1819 (Wong, 2019); and (c) A tutoring di- 
rector does not share a math employment opportunity with POC because the director perceives non-POCs as academically inferior to their White counterparts.

3. Compare with ACCULTURATION, ASSIMILATIONIST (adjective), BIAS, DISCRIMINATION, and RACIST IDEA.

assimilationist (adjective)

1. Definition: Describes the process that a dominant group makes invisible a smaller, powerless group defining characteristics and identity (Yoshino, 2013).

2. Examples: (a) Focusing on Standard Written English in school may be considered an assimilationist pedagogy, as it requires racial and ethnic groups to change or hide their linguistic heritage; (b) reminding immigrant children how fortunate they are to have arrived in the United States; (c) not permitting reading in or using language from the country of origin during class sessions; and (d) not recognizing the common experience of confusion and stressful transition for the immigrant or marginalized U.S. citizens.

3. Compare with ACCULTURATION, ASSIMILATIONIST (noun), BIAS, DISCRIMINATION, and RACIST IDEA.

\section{behavioral antiracist}

1. Definition: "Makes racial group behavior fictional and individual behavior real" (Kendi, 2019, p. 92).

2. Example: Challenging someone who makes a stereotypical statement about everyone within a racial or other identity group.

3. Compare with ANTIRACIST (adjective) and ANTIRACIST (noun).

\section{behavioral racist}

1. Definition: "One who is making individuals responsible for the perceived behavior of RACIAL groups and making RACIAL groups responsible for the behavior of individuals" (Kendi, 2019, p. 92).

2. Example: The false assumption that Black people are more likely to commit crimes than White people. In 2019, White people committed 7 million criminal offenses while Black people committed 2.6 million (Office of Justice Programs, 2019.)

bias

3. Compare with RACIST and CULTURAL RACIST.

1. Definition: (a) Tendency, inclination, or prejudice toward or against something or someone that is preconceived or unreasoned; (b) "stems from the internalization and institutionalization of particular values, beliefs, and assumptions. Not to be confused with BIGOTRY, which is motivated by ill intent, bias can coexist unconsciously with good intentions, but nevertheless result in outcomes that are inclined to favor some groups over others" (Diversity Advisory Council, n.d., section B, para. 1).

2. Examples: (a) Deciding not to conduct an ANTIRACIST staff selection process that ensures that POC are fairly evaluated for a job opening; (b) an Asian American student coming into the center for math tutoring, and the White tutor blurting out, "I thought Asians were supposed to be good at math;" and (c) a student job applicant not being considered for an open position simply because they did not earn an $A$ in a course for which they would like to be selected as a tutor.

3. Compare with: BIGOTRY, DISCRIMINATION, IMPLICIT BIAS, PRIVILEGE, and RACISM.

\section{bigotry}

1. Definition: "Intolerant PREJUDICE which glorifies one's own group and denigrates members of another group" (W.K. Kellogg Foundation, n.d.-a. p. 161).

2. Examples: (a) a group of men in a car driving by and yelling, "Muslim terrorist" at an Hispanic woman who is walking down the street; (b) the campus food service making racial assumptions about food preferences during special receptions it hosts for first-year students by serving fried chicken, collard greens, and macaroni and cheese to welcome first-year Black students and serving tacos for Hispanic or Latinx students at a separate function; and (c) a White hiring manager sharing employment opportunities only with White candidates.

3. Compare with BIAS, DISCRIMINATION, IMPLICIT BIAS, PREJUDICE, PRIVILEGE, and RACISM.

check your privilege

1. Definition: "When someone asks you to "CHECK YOUR PRIVILEGE," they are asking you to pause and consider how the advantages you've had in your life are contributing to your opinions and actions, and how the lack of disadvantages in certain areas is keeping you from fully understanding the struggles others are facing and in fact may be contributing to those struggles" (Oluo, 2019, p. 63).

2. Examples: (a) A White person considering the advantages that being White affords them regarding assumptions about their 
creditworthiness, honesty, trustworthiness, among others; (b) advantages that accompany being the second generation in the family to attend or graduate from college; and (c) having family members who can mentor a younger person as they navigate the challenges of life.

3. Compare with BIAS, IMPLICIT BIAS, and PRIVILEGE.

\section{climate}

1. Definitions: (a) Perceptions and experiences by individual members of the organizational environment; and (b) influences how an individual feels valued, safe, fairly treated, and treated with dignity.

2. Examples: (a) At a learning center, POC experience a CLIMATE of hostility and unwelcomeness toward them due to the attitudes and behaviors of its staff. For example, a staff member assumes that a student of color who comes to the front desk needs a tutor when the student is actually applying for a tutoring or study group job; (b) usually, on predominantly White institutions with few faculty, staff, and administrators who are POC, the CLIMATE is "cold" or "chilly" to Latinx students who attend class or participate in predominantly White clubs; (c) When a Black student walks into a campus honor society meeting with all White students in attendance, the White students stare at the Black student as though they are entering by mistake. The honor society president asks immediately for credentials to validate the Black student's participation but does not ask other White applicants to validate their participation. The Black student begins to feel unwelcomed, and, as a result, the events at the honor society create an atmosphere in which the Black student experiences STEREOTYPE THREAT; and (d) A Black adult male is stopped by the campus police while he is walking across the campus at night, which often happens to African, Black, Hispanic, Indigenous, and Latinx people. The Black male was wearing a dark pea coat and a kufi skull cap. The campus police demanded to know why he was on the campus. He replied that he just finished work after a long day as the Vice-Chancellor for Diversity Affairs and was walking home to have a late dinner with his family in his own neighborhood.

3. Compare with BIAS, BIGOTRY, IMPLICIT BIAS, RACISM, and STEREOTYPE THREAT. cultural antiracist

1. Definition: "Rejects cultural standards and equalizing cultural differences among racial groups" (Kendi, 2019, p. 81).

2. Examples: (a) Appreciating differences and commonalities among artistic expressions such as in art, dance, and music; and (b) using INCLUSIVE curriculum that includes readings by authors from a variety of backgrounds.

3. Compare with ANTIRACIST (adjective), ANTIRACIST (noun), BEHAVIORAL ANTIRACIST, and INCLUSION.

cultural appropriation

1. Definition: "Power imbalance between the CULTURE doing the appropriating and the CULTURE being appropriated. That power imbalance allows the CULTURE being appropriated to be distorted and redefined by the dominant CULTURE and siphons any material or financial benefit of that piece of cultural way to the dominant CULTURE, while marginalized CULTURES are still persecuted for living in that CULTURE. Without that cultural power imbalance, CULTURAL APPROPRIATION becomes much less harmful" (Oluo, 2019, p. 147).

2. Examples: (a) A person taking music, dance, and style from another the Latinx community and profits off it for personal gain without acknowledging the source; (b) a sports team, organization, restaurant, or other commercial establishment using a logo or an image from an Indigenous culture for promotion; and (c) non-Indigenous music festival attendees wearing tribal headdresses as accessories.

3. Compare with CULTURE and MICROAGGRESSION.

\section{cultural racist}

1. Definition: "One who is creating a cultural standard and imposing a cultural hierarchy among RACIAL groups" (Kendi, 2019, p. 81).

2. Example: Black females are considered by some at the bottom of the social hierarchy and therefore, in practice, their contributions during class discussions or in their publications are dismissed or marginalized.

3. Compare with RACIST and BEHAVIORAL RACIST.

\section{culture}

1. Definition: Customary beliefs, social forms, and material traits of a RACIAL, religious, or social group (Merriam Webster, n.d., first definition).

2. Examples: African, Asian, Black, Indige- 
nous, Latinx, Multi-RACIAL, and White.

3. Compare with CULTURAL APPROPRIATION, MICROAGGRESSION, and STEREOTYPE THREAT.

\section{discrimination}

1. Definition: "Unequal treatment of members of a group based on RACE, gender, religion, and other demographics" (Institute for Democratic Renewal and Project Change Anti-Racism Institute, 2019, p. 6).

2. Examples: (a) Due to PREJUDICE, not hiring someone from a particular RACIAL or other identity group; (b) not hiring someone from a particular RACIAL or other identity group due to the belief that there is sufficient representation of that group already present; and (b) Not providing services or making services inaccessible for a particular RACIAL group due to PREJUDICE.

3. Compare with AFFIRMATIVE ACTION, ANTIRACIST DISCRIMINATION, BIAS, BIGOTRY, IMPLICIT BIAS, PREJUDICE, and RACISM.

\section{diversity}

1. Definitions: (a) Wide range of shared and different personal and group characteristics such as nationality, ETHNICITY, RACE, and religion; (b) "aspects of RACE, ETHNICITY, gender, sexual identity, class, and other demographic categories" (Institute for Democratic Renewal and Project Change Anti-Racism Institute, 2019. p. 8); and (c) "embodies inclusiveness, mutual respect, and multiple perspectives and serves as a catalyst for change resulting in EQUITY" (Diversity Advisory Council, n.d., section D, para. 5).

2. Examples: (a) Visible characteristics such as RACE, gender, and age; and (b) “... less obvious characteristics like personality style, ethnicity, ability, prior college experience by family member, economic status, academic preparation, education, living location, religion, job function, life experience, lifestyle, sexual identity, gender identity, geography, regional differences, work experience, and family situation" (Center for Equity, Gender, and Leadership, 2020, para. 38).

3. Compare with CULTURE, ETHNICITY, and RACE.

equality (synonymous with "equal opportunity," a now outdated term)

1. Definition: Ensuring that everyone has similar opportunities for success, such as the same quality of teaching materials, textbooks, and qualified teachers regardless of where they are attending school. The focus is providing an equal starting context for learning rather than similar outcomes for the students. On the other hand, EQUITY is focused on all student demographic groups achieving equal outcomes, such as high school graduation rates, grades, acceptance to college, and graduation rates.

2. Examples: (a) Free test preparation materials and workshops for college admission; (b) financial aid for all students; (c) no use of standardized college admission exams; and (d) colleges employing holistic, asset-based admissions criteria.

3. Compare with AFFIRMATIVE ACTION, EQUITY, INCLUSION, and SOCIAL JUSTICE.

\section{equity}

1. Definitions: (a) "EQUITY recognizes that each person has different circumstances and allocates the exact resources and opportunities needed to reach an equal outcome" (MPH@GW, 2020, para. 2)."EQUITY is a solution for addressing imbalanced social systems. Justice can take EQUITY one step further by fixing the systems in a way that leads to long-term, sustainable, EQUITABLE access for generations to come" (MPH@GW, 2020, para. 5). In contrast, EQUALITY "means [that] each individual or group of people is given the same resources or opportunities" (MPH@GW, 2020, para. 2); (b) "proportional distribution or parity of desirable outcomes across groups. Sometimes confused with EQUALITY, EQUITY refers to outcomes, while EQUALITY connotes equal treatment" (Diversity Advisory Council, n.d., section E, para. 6).

2. Examples: (a) Giving students with certain disabilities accommodations so they can thrive in their classes and earn the same outcomes as students without similar disabilities; (b) providing the services and resources needed for students who are POC to achieve outcome rates for graduation, homeownership rates, and wealth-accumulation that are similar to outcome rates of White students; (c) partially basing public institution funding on the institution's achievement of student demographics that are similar for both graduating and admitted students; and (d) law enforcement treating protestors inequitably, such as the difference in police treatment of Black Lives Matter protestors at Lafayette Park in Washington, DC on June 1, 2020 (where protestors were overwhelmingly met with rubber bullets and tear gas) as compared to the treatment of White protestors who 
stormed the Capitol on January 6, 2021 (where protesters were met only with Capitol police with no call for backup, national guard, or law enforcement presence). But this is "White man's country, so they are allowed to go into the Capitol and take it over. They are allowed to do whatever they want" (BLM activist, personal communication, 2021).

3. Compare with AFFIRMATIVE ACTION, ANTIRACISM, ANTIRACIST, ANTIRACIST DISCRIMINATION, EQUALITY, INCLUSION, and SOCIAL JUSTICE.

\section{ethnic antiracism}

1. Definition: "A powerful collection of ANTIRACIST policies that lead to EQUITY between racialized and ethnic groups and are substantiated by ANTIRACIST ideas about racialized ethnic groups" (Kendi, 2019, p. 56).

2. Examples: (a) An ethnically diverse coalition of faculty, staff, and student employees peacefully protest DISCRIMINATION against Hispanic and Latinx groups regarding their lower salary and inequitable personnel practices; and (b) Black students peacefully protest against prejudice found among White faculty who unfairly grade according to perceived notions that POC students are unable to produce high-quality academic writing (i.e., an African American male in a philosophy class writing an outstanding paper and being unfairly accused of plagiarism because he was from the southwest side of Washington, DC, which is a predominately lower-socio economic section of town).

3. Compare with ALLY, ANTIRACISM (verb), ANTIRACIST (noun), SPACE ANTIRACISM, and SOCIAL JUSTICE.

\section{ethnic racism}

1. Definitions: (a) "powerful collection of RACIST POLICIES that lead to inequity between racialized ethnic groups and are substantiated by RACIST IDEAS about racialized ethnic groups" (Kendi, 2019, p. 56); and (b) racializing ethnic groups serves to create hierarchies of value. RACE becomes more important than ETHNICITY (Kendi, 2019).

2. Examples: (a) A PRIVILEGED English professor assigned lower grades on a Black student's papers because the teacher automatically associated the paper with Ebonics. In this particular case, a White student (a friend of the Black student) swapped names on the paper, and both turned them in to the instructor. Once they received the papers back, they confronted the PRIVILEGED professor because the White student, whose name was on the Black student's paper, received an A grade, while the Black student, whose name was on the White student's paper, received a C. Once confronted, the PRIVILEGED professor said nothing, took both papers from them, walked away, and did not change the grades; and (b) A PRIVILEGED English professor referred one of his Black female students (who was earning straight A's in his class) to interview for a writing center peer tutor position. When she arrived for the interview and asked to see the director, the director (a PRIVILEGED person) stopped her at the door and insisted that she was waiting for another person, yet the director kept saying her name. After several interchanges, with the tone of the director getting nastier and more persistent for her to leave, the Black student said, "My name is so-and-so." The Director was embarrassed and excused herself for a moment, came back, and followed through with the interview. The Black student was subsequently hired for the position.

3. Compare with INSTITUTIONAL RACISM, PASSIVE RACISM, RACISM, SPACE RACISM, and STRUCTURAL RACISM.

\section{ethnicity}

1. Definition: 'Social construct that divides people into smaller social groups based on characteristics such as shared series of group membership, values, behavioral patterns, language, political and economic interests, history, and ancestral geographic location" (Florida Institute of Technology, n.d., para. 15)

2. Examples: Cuban, Hmong, and Mexican.

3. Compare with DIVERSITY and RACE. implicit bias

1. Definition: "Refers to the attitudes or stereotypes that affect our understanding, actions, and decisions in an unconscious manner. These BIASES, which encompass both favorable and unfavorable assessments, are activated involuntarily and without an individual's awareness or intentional control. Residing deep in the subconscious, these BIASES are different from known BIASES that individuals may choose to conceal for the purposes of social and/or political correctness. Rather, IMPLICIT BIASES are not accessible through introspection. The implicit associations we harbor in our subconscious cause us to have feelings and attitudes about other people based on characteristics such as RACE, ETHNICITY, age, and ap- 
pearance. These associations develop over the course of a lifetime beginning at a very early age through exposure to direct and indirect messages. In addition to early life experiences, the media and news programming are often-cited origins of implicit associations" (Kirwan Institute for the Study of Race and Ethnicity, 2012, para. 1-2).

2. Examples: (a) Assuming that some RACIAL groups are better or worse athletes than others for a particular sport; (b) assuming that students of color are often academically underprepared for college-level work; (c) assuming that Asians are better at math than other ethnic groups; and (d) a male White student not wanting to work with a female Black computer science tutor because he assumes that she is not as capable as a White male tutor.

3. Compare with BIAS, BIGOTRY, DISCRIMINATION, PRIVILEGE, and RACISM.

\section{impostor syndrome}

1. Definition: "Also known as IMPOSTORSHIP or IMPOSTOR PHENOMENON, describes a psychological phenomenon in which people are unable to internalize their accomplishments. IMPOSTORSHIP characteristics are largely organized into three subcategories: (1) feeling like a fake, or the belief that one does not deserve one's success; (2) attributing success to luck or other external reasons and not to one's own internal abilities; and (3) discounting success, or the tendency to downplay or disregard achievement of success" (Dancy, 2017, pp. 933).

2. Examples: IMPOSTER SYNDROME may be experienced when (a) A new tutor from a historically underrepresented or disadvantaged background compares themself to other tutors, regardless of having been hired under the same requirements and fulfilling the necessary qualifications; (b) An Asian American professor comes into a new position with a decade of experience does not feel as smart as her peers; and (c) As a Black male, I was marginalized repeatedly by White superiors since they perceived that because I was raised in the "hood," my contributions and background were less than theirs. Furthermore, when I proposed a great idea concerning programming, I was accused of plagiarism or stealing a White colleague's ideas.

3. Compare with CULTURE, MACROAGGRESSION, MICROAGGRESSION, and STEREOTYPE THREAT. inclusion

1. Definitions: (a) "Providing equal educational opportunity by co-creating learning communities in which unique needs and diverse capacities are recognized, understood, accepted, and valued" (Arendale, 2007, p. 21); and (b) "core element for successfully achieving diversity, INCLUSION is created by nurturing the culture and CLIMATE of the institution through professional development, education, policy, and practice. The objective is to create a CLIMATE that fosters belonging, respect, and value for all and encourages engagement and connection throughout the institution and community" (Diversity Advisory Council, n.d., section I, para. 1).

2. Examples: (a) A person of color worked at three predominantly White institutions where they did not experience a CLIMATE of INCLUSION since they were excluded from many decision-making activities. When they began working at a Historic Black College or University (HBCU), they did experience INCLUSION since they were treated as an integral part of the decision-making process; (b) Policies and procedures ensure that resources are accessible to all students; and (c) Advisory boards ensure that multiple student identities are represented.

3. Compare with ANTIRACISM, ANTIRACIST, ANTIRACIST DISCRIMINATION, EQUALITY, and EQUITY.

institutional racism (synonymous with STRUCTURAL RACISM or systemic racism).

1. Definitions: (a) A network of institutional structures, policies, and practices that create advantages and benefits for White people, and DISCRIMINATION, oppression, and disadvantage for people from targeted RACIAL groups. The advantages created for White people are often invisible to them or are considered "rights" available to everyone as opposed to "privileges" awarded to only some individuals and groups (Adams et al., 2007, p. 93); (b) "refers specifically to the ways in which institutional policies and practices create different outcomes for different RACIAL groups. The institutional policies may never mention any RACIAL group, but their effect is to create advantages for whites [sic] and oppression and disadvantage for people from groups classified as non-white" (Potapchuk et al., 2005, p. 39); and (c) "The difference between STRUCTURAL RACISM and MACROAGGRESSSIONS 
is MACROAGGRESSIONS are purposeful, deliberate, and blatantly damaging acts that make an impact at the individual level. STRUCTURAL RACISM is integral to everyday, ordinary interactions" (Osanloo et al., 2016, p. 7).

2. Examples: (a) Government policies that explicitly restrict the ability of people to get loans to buy or improve their homes in neighborhoods with high concentrations of African Americans (also known as "red-lining"); (b) city sanitation department policies that concentrate trash transfer stations and other environmental hazards disproportionately in communities of color (Potapchuk et al., 2005); and (c) admissions departments that do not have POC recruiters may decrease the number of POC who apply since they will not meet someone from a culturally and ethnically diverse background may have experienced similar life experiences and not see someone with whom they can identify.

3. Compare with ETHNIC RACISM, MACROAGGRESSION, MICROAGGRESSION, PASSIVE RACISM, RACISM, and SPACE RACISM

\section{intersectionality}

1. Definitions: (a) "analytical framework through which the relationship among systems of oppression can be understood. African American women made an early contribution to this analysis in the 19th century. Recognizing that they experienced racism and sexism differently from both Black men and White women even while they shared commonalities with both, they argued that a struggle that did not simultaneously address sexism and racism would only perpetuate both" (Diversity Advisory Council, n.d., section I, para. 4); and (b) "SOCIAL JUSTICE movements consider all INTERSECTIONS of identity, PRIVILEGE, and oppression that people face" (Oluo, 2019, p. 7.)

2. Examples: (a) Students from multiple affinity groups collaborating to discuss ways of combating systematic oppression experienced by members of marginalized groups on their campus; and (b) acknowledging the two sets of challenges that a woman of color may face in a field dominated by White men.

3. Compare with CLIMATE and SOCIAL JUSTICE. macroaggressions

1. Definition: "Microassaults conducted in a public forum or sphere, and are buttressed by the nuanced behaviors that exist in a particular or specific context. That is to say, MACROAGGRESSIONS are verbal or non-verbal communications that are not only purposeful and deliberate, but are meant to create longitudinally debilitating and depressive results in the victim. They are persistent and malicious. MACROAGGRESSIONS occur in the nebulous space between MICROAGGRESIONS and INSTITUTIONAL/STRUCTURAL RACISM" (Osanloo et al., 2016, p. 6).

2. Examples: (a) Physical violence; (b) verbal abuse; (c) over-policing Black and Latinx communities; (d) stopping POC drivers or walkers in predominantly White neighborhoods without probable cause; and (e) banks DISCRIMINATING against Black and Latinx families by denying their applications for mortgage loans while granting a loan to a White family with a similar loan application, loan history, and the same available financial assets.

3. Compare with CLIMATE, IMPOSTOR SYNDROME, MICROAGGRESSION, and STRUCTURAL RACISM.

\section{microaggression}

1. Definitions: (a) "Small daily insults and indignities perpetuated against marginalized or oppressed people because of their affiliation with the marginalized or oppressed group and here we are going to talk about RACIAL microaggressions-insults and indignities perpetuated against people of color. But many aggressions are more than just annoyances. The cumulative effect of these constant reminders that you are less valuable than others does real psychological damage. Regular exposure to micro aggressions causes POC to feel isolated and invalidated" (Oluo, 2019, p. 169); (b) the term "ABUSE is used instead of MICROAGGRESION because aggression is not as exacting a term. ABUSE accurately describes the action and its effects on people: distress, anger, worry, depression, anxiety, pain, fatigue, and suicide. What other people call RACIAL MICROAGGRESSIONS, I call RACIST ABUSE" (Kendi, 2019, p. 47); (c) "stunning, automatic acts of disregard that stem from unconscious attitudes of White superiority and constitute a verification of Black inferiority" (Davis, 1989, p. 1576); and (d) "an onslaught of derogatory comments, invalidations, avoidance behaviors, and deficit-laden comments, the experiences may weigh heavy on an individual's spirt, selfworth, and sense of self" (Osanloo et al., 2016, p. 5). 
2. Examples: (a) "Sue et al. (2007) distinguished three types of microaggressions. They are: microassaults; microinsults; and microinvalidations. A microassault is 'an explicit RACIAL derogation characterized primarily by a verbal or nonverbal attack meant to hurt the intended victim through name-calling, avoidant behavior, or purposeful discriminatory actions (p. 274).' ... While explicit, overt, and deliberate, they are deemed 'micro' because they are often conducted on an individual or private level. ... Microinsults are characterized as '... communications that convey rudeness and insensitivity and demean a person's RACIAL heritage or identity. Microinsults represent subtle snubs, frequently unknown to the perpetrator, but clearly convey a hidden insulting message to the recipient of color' (Sue et. al., 2007, p. 274). ... Last, microinvalidations are described as: '... communications that exclude, negate, or nullify the psychological thoughts, feelings, or experiential reality of a person of color' (Sue et al., 2007, p. 274)" (Osanloo et al., 2007, p. 5); (b) ethnic or identity group jokes; (c) singling out POC in the room to speak on behalf of their RACE or other identity group; (d) when visiting the campus learning center multiple times weekly, Catelyn, who is White, speaks to every staff member except Tanisha, who is Black; (e) telling POC that they speak good English (Osanloo et al., 2017) or write very well; (f) crossing to the opposite side of the street when you see a Black man walking in your direction; (g) telling POC that they are "cute but not that bright" because of their ETHNICITY or RACIAL background; (h) a White PRIVILEGED female comparing her tanned arm with that of her Black colleague in order to measure the darkness of her tan; (i) in front of other White colleagues at work, a White person touching the hair of an African American woman to see what dreadlocks feel like and thus interrupting the African American female as she is making her point and contributing to the conversation; (j) a teacher not calling on the first student to raise her hand, who is Black, and instead calling on a White student who raises her hand afterward; (k) a White woman clutching her purse when a Black man sits next to her (Kendi, 2019, p. 46); and (I) a Black person not receiving the same benefit of the doubt when stopped by the police as is given to White youth.
3. Compare with CLIMATE, CULTURAL APPROPRIATION, IMPOSTOR SYNDROME, MACROAGGRESION, STEREOTYPE THREAT, and STRUCTURAL RACISM.

\section{passive racism}

1. Definition: "Beliefs, attitudes, and actions that contribute to the maintenance of RACISM without openly advocating violence or oppression. The conscious and unconscious maintenance of attitudes, beliefs, and behaviors that support the system of RACISM, RACIAL PREJUDICE, and RACIAL dominance" (Wijeysinghe, et al., 1997, p. 89).

2. Examples: (a) During the current year's faculty professional development session on inclusive teaching, a tenured faculty member said that the theme of each year's professional development session centersthe lack of friendliness towards members of marginalized communities as it relates to RACE or ETHNICITY - was untrue and offensive and that we should instead focus on issues related to teaching; (b) Rather than having the admissions director make a formal recruiting presentation accompanied by offers for grants and scholarships to the TRIO Upward Bound (UB) students, the college assumes that these students will automatically apply for admission based upon encouragement from the UB staff. Meanwhile, these same ethnically diverse students are actively recruited and offered grants and scholarships by admissions departments at several surrounding public and private institutions in the city; and (c) White people continue to participate in CULTURAL APPROPRIATION, which is a form of passive racism.

3. Compare with ETHNIC RACISM, INSTITUTIONAL RACISM, SPACE RACISM, and STRUCTURAL RACISM.

\section{prejudice}

1. Definition: "Pre-judgment or unjustifiable, and usually negative, attitude of one type of individual or groups toward another group and its members. Such negative attitudes are typically based on unsupported generalizations (or stereotypes) that deny the right of individual members of certain groups to be recognized and treated as individuals with individual characteristics" (Institute for Democratic Renewal and Project Change Anti-Racism Institute, 2019, p. 15).

2. Examples: (a) Assuming homeless POC are houseless because they have an addiction problem or mental health issues; (b) a 
White student is angry because the teacher put a Black male student in their small group; (c) a White student is angry because of perceived notions of laziness or lack of intelligence of other races and therefore does not include any of the Black student's contributions in a small group project; (d) belief that all Black women are "angry;" (e) belief that all White female college students, especially sorority White females, are sexually promiscuous and (f) locking the car doors when riding through urban neighborhoods perceived as predominately lower-socio economic sections of cities (e.g., North Philadelphia, Homewood section of Pittsburgh, Northeast Minneapolis).

3. Compare with BIAS, DISCRIMINATION, IMPLICIT BIAS, and RACISM.

\section{privilege}

1. Definition: (a) "A right that only some people have access or availability to because of their social group membership. Because hierarchies of PRIVILEGE exist, even within the same group, people who are part of the group in power (White people with respect to people of color, men with respect to women, heterosexuals with respect to homosexuals, adults with respect to children, and rich people with respect to poor people) often deny they have privilege even when evidence of differential benefit is obvious" (Institute for Democratic Renewal and Project Change Anti-Racism Institute, 2019, p. 15); and (b) "These advantages can often be ascribed to certain social groups: PRIVILEGE based on RACE, physical ability, gender, class, etc. But these PRIVILEGES can also lie in areas that you may have not considered, like sexuality, body type, and neurological differences" (Oluo, 2019, p. 60).

2. Examples: (a) A person who is a Brahmin Hindu has access to education loans, jobs, and wealth more easily than those who are not born into this caste; (b) White people are more often given the benefit of the doubt than Black people by police when they are stopped and questioned by them; and (c) White people are more likely than other RACIAL groups to be approved for car and home loans and at lower rates than POC.

3. Compare with BIAS, CHECK YOUR PRIVILEGE, DISCRIMINATION, IMPLICIT BIAS, and RACISM.

race

1. Definitions: (a) "A power construct of collected or merged difference that lives so- cially" (Kendi, 2019, p. 35); and (b) "RACE is a central organizing idea that shapes much of human life across the world. ... Currently, RACE is understood to be socially constructed because the value placed on RA$\mathrm{CIAL}$ groupings reflects a social and political rationale rather than distinct genetic differences. Historically, RACE has been conceptualized using three types of theories: (1) ETHNICITY, (2) class, and (3) nation" (Williams, 2017, p. 1389).

2. Examples: (a) Skin color, (b) ancestral heritage, (c) cultural affiliation, (d) cultural history, and (e) ethnic classification.

3. Compare with DIVERSITY and ETHNICITY. racial equity

1. Definition: "When two or more RACIAL groups are standing on a relatively equal footing" (Kendi, 2019, p. 18).

2. Examples: (a) The rates of homeownerships in a city are nearly the same regardless of RACIAL group; (b) An audit of salaries for employees in a business does not display RACIAL disparity; and (c) Insurance premiums display no differences when analyzed for the RACE of the policyholder.

3. Compare with DISCRIMINATION and RACIAL INEQUITY.

\section{racial healing}

1. Definition: "Racial healing recognizes the need to acknowledge and tell the truth about past wrongs created by individual and systemic racism and address the present consequences. It is a process and tool that can facilitate trust and build authentic relationships that bridge divides created by real and perceived differences. We believe it is essential to pursue racial healing prior to doing change making work in a community. Because, before you can transform systems and structures, you must do the people work first" (W.K. Kellogg Foundation, n.d.-b, p. 5).

2. Examples: (a) Access to quality health care is as easily available and financially accessible in the urban core as it is in the suburbs; (b) Health indicators for POC such as childbirth survivability, diabetes, heart health, and length of life are similar to those of White people; (c) Homeownership rates among POC and White people are similar; (d) Regardless of geographical location, housing occupancy is diverse between POC and White neighborhoods and the city-at-large; (e) Business employees are RACIALLY diverse regardless of work location; and ( $f$ ) Regardless of religious faith, the members of religious congregations are RACIALLY diverse. 
3. Compare with RACIAL HUMILITY and RACIAL RECONCILIATION.

racial humility (synonymous with CULTURAL HUMILITY)

1. Definitions: (a) Learning across the lines of RACIAL difference (Gallardo, 2013); and (b) a look back (at prior RACIAL injustices) in order to move forward (Perkins, 2018).

2. Examples: (a) Engaging in conversations with people of different ethnic groups concerning issues of RACE; (b) a personal or a professional development activity being conducted by learning center staff, tutors, faculty members, or student study group leaders who read, study, and reflect about books on RACE and consider changes in personal actions, attitudes, and words; (c) visiting civil rights sites and learning about the historical events that occurred there and, if possible, visiting the Smithsonian National Museum of African American History and Culture and continuing with a deeper study of the events and conversations with POC; (d) attending an ethno-religious service or social club whose members are of a different ETHNIC group than their own for a significant period of time, talking with the regular attendees, and becoming a learner by listening and observing (Perkins, 2018); (e) attending a branch meeting of the NAACP or the National Urban League in your city or on a college campus; and (f) attending campus events hosted by different RACIAL groups and reflecting about what was seen and heard.

3. Compare with RACIAL HEALING and RACIAL RECONCILIATION.

racial inequity

1. Definition: "When two or more RACIAL groups are not standing on approximately equal footing" (Kendi, 2019, p. 18).

2. Examples: Differences among RACIAL groups regarding (a) access to equal standards of education; (b) access to equal standards of health care, home ownership, job opportunity, retirement savings, salary and benefits, and social capital; and (c) home ownership; over $73 \%$ of White families live in owner-occupied homes, $47 \%$ of Latinx families in owner-occupied homes, and $42 \%$ of Black families in owner-occupied homes (USA Facts, 2020.)

3. Compare with BIAS, BIGOTRY, DISCRIMINATION, and IMPLICIT BIAS, RACIAL EQUITY.

racial policy (synonymous with INSTITUTIONAL RACISM, STRUCTURAL RACISM, and systemic racism).

1. Definition: "By policy, I mean written and unwritten laws, rules, procedures, processes, regulations, and guidelines that govern people. There is no such thing as a nonracist or RACE-neutral policy. Every policy in every institution in every community in every nation is producing or sustaining either RACIAL inequity or equity between RACIAL groups" (Kendi, 2019, p. 18).

2. Examples: (a) offering tutoring sessions and study groups during hours when a higher percentage of students of color are working in comparison to White students; (b) consistently selecting student professionals who are recommended by the classroom instructors for positions of tutors, study group leaders, and other student paraprofessionals without leaving the final decision to the program administrator who can balance applicant experiences with creating a RACIALLY diverse staff; (c) "use of standardized tests to measure aptitude and intelligence is one of the most effective racist policies ever devised to degrade Black minds and legally exclude Black bodies. We degrade Black minds every time we speak of an 'academic achievement gap' based on these numbers. It creates a RACIAL hierarchy with Whites and Asians at the top and Latinx and Blacks at the bottom" (Kendi, 2019, pp. 101-102). The real issue is an opportunity gap rather than an achievement gap, with inequitable funding between predominantly Black and White schools for curriculum, teacher-student ratios, and per-pupil expenditures (Kendi, 2019).

3. Compare with RACISM, STRUCTURAL RACISM, and systemic racism.

racial reconciliation

1. Definitions: (a) "Involves three ideas. First, it recognizes that RACISM in Ameri$\mathrm{ca}$ is both systemic and institutionalized, with effects on both political engagement and economic opportunities for minorities. Second, reconciliation is engendered by empowering local communities. Lastly, justice is the essential component of the conciliatory process-justice that is best termed as restorative rather than retributive, while still maintaining its vital punitive character" (William Winter Institute for Racial Reconciliation, 2007, para. 2); (b) The first step in RECONCILIATION is seeing the problem, not just the solution. "We've not been able to arrive at the solution because we haven't acknowledged the problem" (Perkins, 2018, p. 16); and (c) "Biblical REC- 
ONCILIATION is the removal of tension between parties and the restoration of loving relationships" (Perkins, 2018. p. 17).

2. Examples: (a) In 2018, the City of Charleston City Council formally recognized and apologized for its role in the slave trade. The city also pledged to create an office for RACIAL reconciliation to help with healing (Gomez, 2018); and (b) The city government of Evanston, Illinois, created a city reparations fund for local African Americans by using sales tax income on recreational marijuana (Lutz, 2020).

3. Compare with RACIAL HEALING and RACIAL HUMILITY.

racism

1. Definitions: (a) "Marriage of RACIST POLICIES and RACIST IDEAS that produces and normalizes RACIAL inequities" (Kendi, 2019, p. 18); and (b) "specific ways in which institutional policies and practices create different outcomes for different RACIAL groups. The policies may never mention specific RACIAL groups, but their effect is to create advantages for Whites [sic] and oppression and disadvantage for people from groups classified as non-White" (W.K. Kellogg Foundation, n.d.-a, p. 164).

2. Examples: See examples for ETHNIC RACISM, INSTITUTIONAL RACISM, PASSIVE RACISM, SPACE RACISM, and STRUCTURAL RACISM.

3. Compare with ETHNIC RACISM, INSTITUTIONAL RACISM, PASSIVE RACISM, SPACE RACISM, and STRUCTURAL RACISM.

racist (adjective)

1. Definitions: (a) "One who is supporting a RACIST POLICY through their actions or inaction or expressing a RACIST IDEA" (Kendi, 2019, p. 9); and (b) "But there is no neutrality in the racism struggle. The opposite of 'RACIST' is 'antiracist'”' (Kendi, 2019, p. 10).

2. Examples: See BEHAVIORAL RACIST and CULTURAL RACIST.

3. Compare with BEHAVIORAL RACIST and CULTURAL RACIST.

\section{racist idea}

1. Definitions: (a) "Any idea that suggests one RACIAL group is inferior or superior to another RACIAL group in any way. RACIST IDEAS argue that the inferiorities and superiorities of RACIAL groups explain RACIAL inequities in society" (Kendi, 2019, p. 20). "The source of RACIST IDEAS was not ignorance and hate, but self-interest" (Kendi, 2019, p. 230); and (b) "make people of color think less of themselves, which make them more vulnerable to RACIST IDEAS and makes White people think more of themselves, which further attracts them to RACIST IDEAS" (Kendi, 2019, p. 6).

2. Examples: (a) The idea that there is a hierarchy of opportunity, of which the PRIVILEGED White male sits at the top, and the Black female sits at the bottom; (b) the false belief that most welfare recipients are Black people when actually the majority are White people. The majority of Black people refuse to accept welfare assistance (Kendi, 2019); (c) false assumption that Black neighborhoods have a higher rate of crime than White neighborhoods (Kendi, 2019); (d) terrorist are most have roots from the Middle East countries; and (e) most Black women are angry and loud.

3. Compare with RACISM.

space antiracism

1. Definition: "Powerful collection of ANTIRACIST policies that lead to racial EQUITY between integrated and protected racialized spaces, which are substantiated by ANTIRACIST IDEAs about racialized spaces" (Kendi, 2019, p. 166).

2. Examples: (a) Classrooms for developmental-level courses and the offices of those who teach them are of the same quality as those for the undergraduate education classes; (b) Learning centers, tutoring centers, and educational equity grant programs such as TRIO are easily and quickly accessed by students through nearby parking lots and campus shuttles; (c) Office, meeting, and classroom spaces used by educational equity grant programs such as TRIO are similar those of undergraduate education programs; (d) Public bus routes to the campus offer frequent bus connections; and (e) Institutionally-sponsored bus routes are provided to ensure easy access for students who live in lower-economic neighborhoods for easy pickup and connection to the public bus or transit system.

3. Compare with ANTIRACISM (verb), ANTIRACIST (noun), ETHNIC ANTIRACISM, and SOCIAL JUSTICE.

\section{space racism}

1. Definition: "Powerful collection of RACIST POLICIES that lead to resource inequity between racialized spaces or the elimination of certain racialized spaces, which are substantiated by RACIST IDEAS about racialized spaces" (Kendi, 2019, p. 166).

2. Examples: (a) Locating ethnic cultural centers in the basements of old buildings which 
takes them away from the natural flow of students through the college campus; (b) locating learning centers which serve a culturally-diverse group of students in buildings without nearby parking lots or not close to campus bus routes making it inconvenient for students to access, especially during unsafe weather conditions; (c) locating academic support services which serve a diverse population of students, especially those from marginalized backgrounds in the oldest and most dilapidated campus buildings; (d) campus security officers more often stopping Black people than White people to check why they are on campus; (e) campus buildings of taxpayer-funded institutions that are locked and only admissible with the presentation of an institution-issued identity card, which creates an unfriendly atmosphere for staff and students, especially for those that are first-generation college and find the college experience unfamiliar and sometimes intimidating; ( $f$ ) real estate agents steering prospective homeowners to neighborhoods of similar demographics (ETHNICITY and RACE) despite having credit ratings that allow them to purchase more expensive homes in predominantly White neighborhoods (Tatum, 2017); and (g) EQUITY programs such as TRIO being assigned by senior college administrators to old offices and classroom spaces abandoned by academic departments with hand-me-down furniture, old equipment, and dilapidated facility conditions. This treatment creates an impression of the low priority for the program by the campus administrators and diminished importance for the students who are often from diverse and marginalized backgrounds.

3. Compare with ETHNIC RACISM, INSTITUTIONAL RACISM, PASSIVE RACISM, RACISM, and STRUCTURAL RACISM.

\section{structural racism}

1. Definition: STRUCTURAL RACISM is within systems and organizations. The RACISM is embedded into and throughout the everyday policies, rules, and regulations that are not neutral, but rather afford advantages to one or more RACES over others.

2. Examples: (a) It is not unusual within an urban high-school for textbooks to be used and out-of-date while suburban students have newer books and learning resources due to their higher per capital funding for the students; and (b) Immigration policies favor northern Europe and exclude or se- riously reduce applicants from Africa and the Middle East (Kendi, 2019); "When Congress ended the national-origins quotas in the 1960s, lawmakers implemented a policy of seemingly "equal" country caps in order to limit legal immigration from Mexico and countries in Asia (Cook-Martin \& Fitzgerald, 2014, para. 5).

3. Compare with ETHNIC RACISM, INSTITUTIONAL RACISM, PASSIVE RACISM, and SPACE RACISM.

\section{social justice}

1. Definitions: (a) The condition in which all people have equal access to education, employment, wealth, healthcare, well-being, justice, freedom, and opportunity; (b) a vision of society in which the distribution of resources is equitable and all members are physically and psychologically safe and secure (Adams et al., 2007); and (c) "individuals are both self-determining (able to develop their full capacities) and interdependent (capable of interacting democratically with others). SOCIAL JUSTICE involves social actors who have a sense of their own agency as well as a sense of social responsibility toward and with others, their society, and the broader world in which we live. These conditions we wish not only for own society but also for every society in our interdependent global community. The process of attaining the goal of SOCIAL JUSTICE should also be democratic and participatory, inclusive and affirming of human agency and human capabilities for working collaboratively to create change. The goal of SOCIAL JUSTICE education is to enable people to develop the critical analytical tools necessary to understand oppression and their socialization within oppressive systems and to develop a sense of agency and capacity to interrupt and change oppressive patterns and behaviors in themselves and in the institutions and communities they are a part" (Bell, 2007, pp. 1-2).

2. Examples: (a) All people have equal access (EQUALITY) to education, employment, wealth, healthcare, well-being, justice, freedom, and opportunity; all people receive EQUITABLE outcomes from their education and employment regarding wealth, health, well-being, justice, freedom, and opportunity; and (c) access to distribution of resources, namely the COVID vaccine, is equally distributed to ethnic minorities and the poor.

3. Compare with ANTIRACISM, ANTIRACIST, ANTIRACIST DISCRIMINATION, EQUALITY, EQUITY, and INCLUSION. 


\section{stereotype threat}

1. Definition: Risk of a person confirming unwarranted negative academic capability stereotypes based on an individual's RACIAL, ETHNIC, gender, or cultural group. This creates fear about academic failure, which results in difficulty focusing on academic tasks and lowering academic performance rather than predictions based on the person's academic preparation (Steele \& Aronson, 1998).

2. Examples: (a) An academic advisor says that some students from Asian and White student groups will be naturally more successful in STEM academic majors than other RACIAL groups and therefore they should consider other academic majors and (b) a test administrator says to a group of ethnically diverse students that a highstakes assessment will likely be a critical gatekeeper of whether a student is admitted to a highly selective STEM program.

3. Compare with CULTURE and IMPOSTOR SYNDROME.

\section{tone policing}

1. Definition: "When someone (the PRIVILEGED person) in a conversation or situation about oppression shifts the focus of the conversation from the oppression being discussed to the way it has been discussed. TONE POLICING prioritizes the comfort of the PRIVILEGED person in the situation over the oppression of the disadvantaged person" (Oluo, 2019, pp. 205206).

2. Examples: (a) A White teacher or tutor telling POC to lower the volume of their conversation; (b) one person stating the other is acting too emotional while they are talking; (c) During a conversation about the history of racism perpetuated on Black and Indigenous populations, Jeremy (a White student), admonishes William (a Black student), for his emphatic manner of speaking in which he raises his voice when speaking about the topic, rather than the topic itself; (d) belief that an angry Black woman should refrain from conversations that may make her appear angry in a meeting; and (e) White resident assistants repeatedly telling the TRIO Upward Bound students they are too loud in the residence hall at night during their summer program while not doing the same for the White summer school residents in the same facility.

3. Compare with PRIVILEGE and RACISM.
Author Note

We owe much to the expertise of the authors, editors, and external review teams that created other race glossaries. We cited their work frequently in our glossary. Secondly, we acknowledge the Colleagues of Color for Social Justice (CCSJ). The coauthors of this glossary are members of that group. The CCSJ was created in fall 2020 to provide a forum for people of color in higher education to produce publications and media projects that intersect with race and social justice. This group will grow organically as we conduct our work. From a brief invitation in fall 2020 through a single email listserv, the group has grown to more than 50 participants. They serve in a variety of roles in academic affairs, enrollment management, and student affairs at various levels of their institutions. After starting with an initial set of writing and media projects, any member of CCSJ can propose new writing and media projects for others in the group to join. Periodically, the group will revisit the group name, purpose, composition, and projects. More information about CCSJ members and their publications and media are available at www.socialjustice. work. Currently, members are at various stages with a dozen publications and are contributing to our blog and Twitter channel. In the future, they will add a YouTube channel and Facebook page.

\section{Disclosure Statement}

No potential conflict of interest was reported by the authors.

\section{About the Authors}

Richa Pokhrel is the data coordinator with the Center for Student Learning at the College of Charleston in South Carolina. Her research interests are equity and inclusion. She has published in The Learning Assistance Review.

Mursalata Muhammad is a faculty member in the English Department at Grand Rapids Community College in Michigan. Her research interests are reflective educational practices, human literacy skills, and culturally competent education policies. She was previously published in Student Dialogues: Community College Case Studies to Consider.

Juan Jimenez is the associate dean for general studies at Western Technical College in Wisconsin. His research interests are diversity, equity, and inclusion.

Dr. Cassandra C. Green is the assistant vice-president for the Office of Student Success at Delaware State University. Her research interests are in developing and assessing student learning outcomes for retention-based programs and teaching mind-mapping and cognitive learning techniques that increase college student learning and study. 
Dr. Sarah Felber is a professor and leader in the Writing Across the Curriculum Program at the University of Maryland Global Campus. Her research interests include literacy education, online and adult learning, and equity and justice issues. She serves as co-editor of the Journal of College Reading and Learning and has recently published work in the Online Journal of Distance Learning Administration and MLA Style Center.

Chardin Claybourne is a faculty member with Learning Lab and Tutoring Services at Henry Ford College in Michigan. His research interests are learning assistance, diversity, equity, and inclusion.

WyKeshia Atkins is the director of Learning Assistance Programs at Southeast Missouri State University. Her research interests are learning assistance, diversity, equity, and inclusion.

Dr. David R. Arendale is an associate professor emeritus of history in the Curriculum and Instruction Department at University of Minnesota-Twin Cities. His research interests include learning assistance, equity, inclusion, and Universal Design in Learning. He has published in a variety of journals, including the Journal of Developmental Education and the Journal of Peer Learning.

\section{References}

Adams, M., Bell, L. A., \& Griffin, P. (Eds.) (2007). Teaching for diversity and social justice: $A$ sourcebook. Routledge.

Arendale, D. R. (2007). Aglossary of developmental education and learning assistance terms. Journal of College Reading \& Learning, $38(1), 10-34$.

Bell, L. A. (2007). Theoretical foundation for social justice education. In M. A. Adams, L. A. Bell, \& P. Griffin. (Eds.). Teaching for diversity and social Justice (2nd ed., pp. 1-14). Routledge.

Berkner Botyt, M. M. (2020, April 20). 19 for 19: Mini language \& dictionary guide for COVID-19. LinkedIn. https://www.linkedin. com/pulse/19-19mini-language-dictionary-guide-covid-19-maureen-berknerboyt/?trk=public profile article view

Center for Equity, Gender, and Leadership. (2020). Glossary of key terms. Hass School of Business at the University of California, Berkeley. https://haas.berkeley.edu/equity/industry/efl-knowledge-bank/glossaryof-key-terms/

Cook-Martin, D., \& Fitzgerald, D. (2014). How legacies of racism persist in U.S. Immigration policy. Scholars Strategy Network. https://scholars.org/contribution/ how-legacies-racism-persist-us-immigration-policy
Dancy, T. (2017). Impostor syndrome. In K. Nadal (Ed.), The SAGE encyclopedia of psychology and gender (p. 933-934). SAGE Publications. https://sk.sagepub. com/reference/the-sage-encyclopediaof-psychology-and-gender

Davis, P. (1989). Law as microaggression. Yale Law Journal, 98(8), 1559-1577.

Diangelo, R. (2018). White fragility. Beacon Press.

Diversity Advisory Council. (n.d.). Diversity advisory council: Glossary. https://www.umaryland.edu/diversity/dei-resources/glossary/

Florida Institute of Technology. (n.d.). Culturally competent terms. https://www.fit.edu/cultural-competency-certificate/culturally-competent-terms/

Gallardo, M. E. (2013). Developing cultural humility: Embracing race, privilege, and power. SAGE.

Gomez, M. (2018, June 19). Charleston apologizes for city's role in slave trade. The New York Times. https://www.nytimes. $\mathrm{com} / 2018 / 06 / 19 / \mathrm{us} / \mathrm{charleston-slav-}$ ery-apology.html

Inoue, A. B. (2020). Teaching antiracist reading. Journal of College Reading and Learning, 50(3), 134-156. https://doi.org/10.1080/1 $\underline{0790195.2020 .1787079}$

Institute for Democratic Renewal and Project Change Anti-Racism Institute. (2019). A community builder's toolkit. Racial Equity Tools. Author.

Kendi, I. X. (2019). How to be an antiracist. One World Press.

Kirwan Institute for the Study of Race and Ethnicity. (2012). Understanding implicit bias. https://kirwaninstitute.osu.edu/article/understanding-implicit-bias

Legal Information Institute. (n.d.) Affirmative action. In Wex legal dictionary. Retrieved July 11, 2021, from https://www.law.cornell. edu/wex/affirmative action

Ludema, J., \& Johnson, A. (2020, August 4). How to be an ally for colleagues of color at work: Three do's and don'ts for taking action. Forbes. https://www.forbes.com/sites/amberjohnson-jimludema/2020/08/04/how-to-be-anally/?sh=469aa6472a42

Lutz, E. (2020, January 19). One city's reparations program that could offer a blueprint for the nation. The Guardian Newspaper. https:// www.theguardian.com/us-news/2020/ jan/19/reparations-program-evanston-illinois-african-americans-slavery

Makarova, E., \& Birman, D. (2016). Minority students' psychological adjustment in the school context: An integrative review of qualitative research on acculturation. Intercultural Education, 27(1), 1-21. https:// doi.org/10.1080/14675986.2016.1144382 
McCoy, H. (2020, June 12.) The life of a Black academic: Tired and terrorized. Inside Higher Ed. https://www.insidehighered.com/advice/2020/06/12/terror-many-black-academics-are-experiencing-has-left-them-absolutely-exhausted\#.XuOPhwe9oAg.link

Merriam Webster. Culture. In Merriam Webster Dictionary. https://www.merriam-webster.com/ dictionary/culture

MPH@GW, the George Washington University Online Master of Public Health Program. (2020, November 5). Equity vs. equality: What's the difference? https://onlinepublichealth.gwu. edu/resources/equity-vs-equality/

National Museum of African American History \& Culture. (n.d.) Talking about race. https:// nmaahc.si.edu/learn/talking-about-race

Office of Justice Programs. (2019). Statistical briefing book. https://www.ojidp.gov/ojstatbb/ crime/ucr.asp?table in $=2$

Oluo, I. (2019). So you want to talk about race. Seal Press.

Osanloo, A. F., Boske, C., \& Newcomb, W. S. (2016). Deconstructing macroaggressions, microaggressions, and structural racism in education: Developing a conceptual model for the intersection of social justice practice and intercultural education. International Journal of Organizational theory and Development, 4(1), 1-18. https://tinyurl.com/kukvab75

Perkins, J. M. (2018). One blood: Parting words to the church on race and love. Moody Publishers.

Potapchuk, M., Leiderman, S., Bivens, D., \& Major, B. (2005). Flipping the script: White privilege and community building. MP Associates; Center for Assessment and Policy Development. http://www.mpassociates.us/uploads/3/7/1/0/37103967/flippingthescriptmostupdated.pdf

Race Forward. (2015). Race Forward reporting guide. http://raceforward.org/reporting-guide

Roberts, J. (2020, June 8). White academia: Do better. Medium. https://medium.com/the-faculty/ white-academia-do-better-fa96cede1fc5

Steele, C. M., \& Aronson, J. (1998). Stereotype threat and the test performance of academically successful African Americans. In C. Jencks \& M. Phillips (Eds.), The Black-White test score gap (pp. 401-427). Brookings Institution Press.

Sue, D. B., Capodilupo, C., Torino, G., Bucceri, J., Holder, A., Nadal, K., \& Esquilin, M. (2007). Racial microaggressions in everyday life: Implications for clinical practice. American Psychologist, 6(4), 271-286.

Tatum, B. D. (2017). Why are the Black kids sitting together in the cafeteria? And other conversations about race. Basic Books.
USA Facts. (2020). Black Americans are currently the least likely group to own homes. https://usafacts.org/articles/homeownership-rates-by-race/

Wijeysinghe, C. L., Griffin, P, and Love, B. (1997). Racism curriculum design. In M. Adams, L. A. Bell, \& P. Griffin (Eds.), Teaching for diversity and social justice: A sourcebook (pp. 82-109). Routledge.

William Winter Institute for Racial Reconciliation. (2007). Racial reconciliation and racial healing. http://archive.racialequitytools.org/act/ strategies/racial-reconciliation-and-racial-healing

Williams, W. (2017). Race and gender. In K. Nadal (Ed.), The SAGE encyclopedia of psychology and gender (pp. 1389-1392). SAGE Publications, Inc. https://www-doi-org.ezp1.lib. umn.edu/10.4135/9781483384269.n466

W.K. Kellogg Foundation. (n.d.-a) Racial equity resource guide. https://www.canr.msu.edu/ od/uploads/files/Multiculturalism Diversity/Racial Equity Resource Guide1.pdf

W.K. Kellogg foundation (n.d.-b) Restoring to wholeness: Racial healing for ourselves, our relationships, and our communities. https://www.ala.org/tools/sites/ala.org. tools/files/content/Restoring\%20to\%20 Wholeness\%20WKKF\%20Racial\%20Healing\%20Publication.pdf

Wong, A. (2019, March 5). The schools that tried-but failed-to make Native Americans obsolete. The Atlantic. https://www.theatlantic.com/education/ archive/2019/03/failed-assimilation-native-american-boarding-schools/584017/

Yoshino, K. (2013). Assimilationist bias in equal protection: The visibility presumption and the case of "Don't Ask, Don't Tell." The Yale Law Journal, 108, 485-571. https://digitalcommons.law.yale.edu/cgi/ viewcontent.cgi ?article $=5388 \&$ contex$\mathrm{t}=\mathrm{fss}$ papers 